\title{
Performance and organ characteristics of broiler chickens fed varying levels of rumen content
}

${ }^{1}$ Umar, A. M., ${ }^{2}$ Daninna, A. U., ${ }^{1}$ Muazu, M. S., ${ }^{1}$ Kirfi, A. M., ${ }^{1}$ Abdullahi, M., ${ }^{3}$ Nuhu, Y. A. and ${ }^{3}$ Yakubu, Z. M.

${ }^{\prime}$ Department of Animal Production, Abubakar Tafawa Balewa University, Bauchi.

${ }^{2}$ School of Rural Technology and Entrepreneurship Development, Kano State Polytechnic, Kano, Nigeria.

${ }^{3}$ Pre-ND Department, Audu Bako College of Agriculture, Danbatta, Kano.

Abstract

A trial was carried out to evaluate the effect of replacing wheat offal with rumen content on the growth performance of broiler chickens. A total of one hundred and fifty (150), one dayold broiler chicks were randomly allotted to five (5) dietary treatments containing 0, 5, 10\% inclusion levels of sundried rumen content and 5 and $10 \%$ inclusion levels of roasted rumen content as a replacement to wheat offal. Each treatment was replicated three times with five (5) birds per replicate in a completely randomized design experiment. The trial lasted for eight (8) weeks. The results showed that there were no significant differences in the final weights, daily feed intake, daily weight gain and feed conversion ratio at the starter phase and finisher phases. Furthermore, no significant differences in the final weight (1346.601508.50g), daily feed intake (83.57-100.00g), and daily weight gain (36.43-39.53g), and were observed for the overall performance. However, there was a significant difference $(P<0.05)$ in the feed conversion ratio with the highest being $2.69 \mathrm{~g}$ and the lowest $2.33 \mathrm{~g}$ in the overall performance. From these findings, it could be concluded that rumen content could replace wheat offal without any detrimental effect on the performance of broiler chickens.

Keywords: Rumen content, broiler, chicken and organ.

\section{Introduction}

A major problem facing the development of broiler chicken production is the availability and high cost of feedstuff. A significant cost of production faced by poultry farmers is that of feed $(55-70 \%)$ and because it is usually unaffordable by the poor peasant farmers, the output is generally poor, thus leading to a shortage in the availability of protein to the citizenry (Atteh, 2003). There is also competition between man and poultry for conventional feedstuff like maize, wheat, soya bean among others. There is, therefore, the need for alternative and non-conventional feedstuffs to be used (Biobaku et al., 1999). Rumen content is a solid waste generated daily at abattoirs in Nigeria with about 50,000 metric tonnes available per year (Makinde, 2008). The content is made up of plant materials at various stages of digestion and is rich in microbial protein (Emmanuel
1978; McDonald et al., 1990). The nutrient content and chemical composition of the diets destined for poultry feeding have been modified in the last decade with the aim of improving feed intake and productivity. An increase in nutrient concentration and digestibility of the ingredients together with a reduction in feed particle size to improve quality are some of the changes introduced. The implementation of these strategies has resulted in a decrease in crude fibre content of the diets and variations of the overall structure of the feed. The growth in Nigeria's poultry sector is constrained by the persistent scarcity and high cost of major feed inputs such as corn and soya bean meals. On the other hand, there is a need to increase animal productivity in order to make animal protein sources available and more affordable to Nigeria's populace. This could be enhanced by turning discarded rumen content to a useful 


\section{Performance and organ characteristics of broiler chickens fed varying levels of rumen content}

source of nutrient. Esonu et al. (2006) and Dairo et al. (2006) state that rumen content is the consumed plant material that ruminant animals ingest and is later harvested while it is at various stages of digestion. It is rich in protein and other micro-flora such as fungi, protozoa, and bacteria. Rumen content from cattle and other ruminants like sheep and goats is a substantial waste that is readily available daily at abattoirs (Odunsi et al., 2004). Although, monogastric species cannot digest cellulose and other fibrous materials in rice milling waste, yet the available protein in rumen digesta can be utilized by broilers to obtain useful nutrients. Therefore, the use of rumen digesta can reduce feed costs thereby increasing the rate of profit to the poultry producers. The study was therefore conducted to assess the performance and organ characteristics of broiler chickens fed diets containing varying levels of rumen content.

\section{Materials and method Experimental site}

The research was carried out at the poultry research farm of Bauchi State College of Agriculture. The college is located at Yelwan along Tafawa Balewa road in Bauchi Local Government Area of Bauchi State. The State lies between longitude $10^{\circ} 10^{1}$ to $30^{1} \mathrm{~N}$ and latitude 9041 and $10^{0} 31^{1} \mathrm{E}$ at an altitude of 6902 metres above sea level (Bauchi State Agricultural Development Programme, nd).

\section{Experimental birds and their management}

A total of 150, day-old chicks were purchased from Zartech hatchery. The chicks were brooded in well ventilated pens for two weeks and fed commercial feed during the brooding period. After brooding, chickens were randomly allotted to five experimental treatments, each treatment was replicated three times with ten birds per replicate. Vaccination of the birds with infectious bursal disease vaccine (IBDV) was conducted at the first week and repeated at third week, while Newcastle disease vaccine (Lasota) was administered at the second and fourth weeks. The experimental diet and water were given adlibitum from the second week up to the eighth week of the study. Medications were also administered during this experimental period.

\section{Experimental diets}

Five diets were formulated as diets A, B, C, $\mathrm{D}$ and $\mathrm{E}$, each for the starter and finisher phases. Diet A for both the starter and finisher phases did not have rumen content (i.e control) while diet B, C, D and E contained rumen content as a replacement to wheat offal. Diet B and C comprised of sun dried rumen content at $5 \%$ and $10 \%$ levels of inclusion respectively, while roasted rumen content was included also at $5 \%$ and $10 \%$ in diets $\mathrm{D}$ and $\mathrm{E}$, respectively. The various diets were compounded manually; the starter contained $23 \%$ crude protein while the finisher contained $21 \%$ crude protein. The percentage composition and calculated analysis of the experimental diets are shown in the Tables 1 and 2.

\section{Experimental design}

The experimental design was a completely randomized design (CRD). Five different diets formed the treatments and each treatment was replicated three times with ten birds per replicate.

\section{Data collection}

The experiment lasted for eight (8) weeks during which data were collected from the third to eighth week on several parameters monitored. Feed intake was calculated by deducting left over from feed offered. Birds were weighed using a weighing scale while weight change was determined by subtracting the initial weight from the final weight.

\section{Data analysis}

Data collected were subjected to analysis of variance using SPSS statistical package 21 and least significance differences (LSD) were differentiated as described by Steel and Torrie (1984). 
Umar, Daninna, Muazu, Kirfi, Abdullahi, Nuhu and Yakubu

Table 1: Composition of experimental diets at starter phase

\begin{tabular}{|c|c|c|c|c|c|}
\hline \multirow[b]{3}{*}{ Ingredients } & \multirow[b]{3}{*}{ A $(0 \%)$} & \multicolumn{4}{|c|}{ Diets } \\
\hline & & \multicolumn{2}{|c|}{ SRC } & \multicolumn{2}{|c|}{ RRC } \\
\hline & & B (5\%) & $\mathrm{C}(10 \%)$ & D (5\%) & E $(10 \%)$ \\
\hline Maize & 50.70 & 50.70 & 50.70 & 50.70 & 50.70 \\
\hline Soya bean meal & 33.00 & 33.00 & 33.00 & 33.00 & 33.00 \\
\hline Wheat offal & 10.00 & 5.00 & - & 5.00 & - \\
\hline Rumen content & - & 5.00 & 10.00 & 5.00 & 10.00 \\
\hline Fish meal & 2.00 & 2.00 & 2.00 & 2.00 & 2.00 \\
\hline Bone meal & 2.00 & 2.00 & 2.00 & 2.00 & 2.00 \\
\hline Limestone & 1.50 & 1.50 & 1.50 & 1.50 & 1.50 \\
\hline Premix & 0.25 & 0.25 & 0.25 & 0.25 & 0.25 \\
\hline Salt & 0.25 & 0.25 & 0.25 & 0.25 & 0.25 \\
\hline Methionine & 0.10 & 0.10 & 0.10 & 0.10 & 0.10 \\
\hline Lysine & 0.10 & 0.10 & 0.10 & 0.10 & 0.10 \\
\hline Toxail binder & 0.10 & 0.10 & 0.10 & 0.10 & 0.10 \\
\hline TOTAL & 100.00 & 100.00 & 100.00 & 100.00 & 100.00 \\
\hline
\end{tabular}

$S R C=$ sun dried rumen content; $R R C=$ roasted rumen content

$A=0 \% ; B=5 \%$ SRC, $C=10 \%$ SRC, $D=5 \%$ RRC, $E=10 \% R R C$

Table 2: Composition of experimental diets at finisher phase

\begin{tabular}{llllll}
\hline Ingredient & A & B & C & D & E \\
\hline Maize & 49.60 & 49.60 & 49.60 & 49.60 & 49.60 \\
Soya bean meal & 29.10 & 29.10 & 29.10 & 29.10 & 29.10 \\
Wheat offal & 15.00 & 7.50 & - & 7.50 & - \\
Rumen content & - & 7.50 & 15.00 & 7.50 & 15.00 \\
Fish meal & 2.00 & 2.00 & 2.00 & 2.00 & 2.00 \\
Limestone & 1.50 & 1.50 & 1.50 & 1.50 & 1.50 \\
Lysine & 0.10 & 0.10 & 0.10 & 0.10 & 0.10 \\
Methionine & 0.10 & 0.10 & 0.10 & 0.10 & 0.10 \\
Premix & 0.25 & 0.25 & 0.25 & 0.25 & 0.25 \\
Salt & 0.25 & 0.25 & 0.25 & 0.25 & 0.25 \\
Toxil binder & 0.10 & 0.10 & 0.10 & 0.10 & 0.10 \\
Bone meal & 2.00 & 2.00 & 2.00 & 2.00 & 2.00 \\
TOTAL & $\mathbf{1 0 0 . 0 0}$ & $\mathbf{1 0 0 . 0 0}$ & $\mathbf{1 0 0 . 0 0}$ & $\mathbf{1 0 0 . 0 0}$ & $\mathbf{1 0 0 . 0 0}$ \\
\hline
\end{tabular}

$S R C=$ sun dried rumen content; $R R C=$ roasted rumen content

$A=0 \% ; B=5 \%$ SRC, $C=10 \%$ SRC, $D=5 \%$ RRC, $E=10 \% R R C$

\section{Results}

Performance of broiler chickens fed graded levels of rumen content based diets at starter phase

The performance of broiler chickens fed graded levels of rumen content is presented in Table 3. All values obtained were not significantly different among the treatments. The initial weight ranged from $118.75 \mathrm{~g}$ in birds on diet A to $123.75 \mathrm{~g}$ in chicks on diet $\mathrm{B}$. The final weights obtained were $668.75 \mathrm{~g}, 666.67 \mathrm{~g}, 611.46 \mathrm{~g}$ and $639.58 \mathrm{~g}$ for diets $\mathrm{A}, \mathrm{B}, \mathrm{C}, \mathrm{D}$ and $\mathrm{E}$, respectively. The daily feed intake varied from $49.42 \mathrm{~g}$ in chicks fed diet $\mathrm{D}$ to $50.74 \mathrm{~g}$ in birds on diet A. The daily weight gain was found to be $19.57 \mathrm{~g}, 18.53 \mathrm{~g}, 18.38 \mathrm{~g}$, $19.24 \mathrm{~g}$ and $17.34 \mathrm{~g}$ for $\operatorname{diet} \mathrm{A}, \mathrm{D}, \mathrm{B}, \mathrm{E}$ and C respectively; however, all the daily weight gains were similar. The higher feed conversion value was obtained in birds on diets $\mathrm{C}$ while the lowest value was obtained in $\operatorname{diet} \mathrm{A}$. 
Performance and organ characteristics of broiler chickens fed varying levels of rumen content

Table 3: Performance of broiler chickens fed graded levels of rumen content based diet at starter phase

\begin{tabular}{lccccccc}
\hline Parameter & A (0\%) & B (5\%) & C (10\%) & D (5\%) & E (10\%) & SEM & LS \\
\hline Initial weight & 118.75 & 123.75 & 116.88 & 120.63 & 115.92 & 1.20 & NS \\
Final weight & 668.75 & 666.46 & 611.46 & 49.42 & 600.46 & 56.00 & NS \\
Daily feed intake & 50.74 & 49.62 & 49.59 & 49.42 & 49.45 & 1.34 & NS \\
Daily weight gain & 19.57 & 18.38 & 17.34 & 18.53 & 18.35 & 1.30 & NS \\
FCR & 2.26 & 2.87 & 2.87 & 2.66 & 2.75 & 0.35 & NS \\
\hline
\end{tabular}

SEM $=$ Standard Error of Mean; $N S=$ Not Significant $; F C R=$ Feed Conversion Ratio, $\quad S R C=$ sun dried rumen content; $R R C=$ roasted rumen content

$A=0 \% ; B=5 \%$ SRC, $C=10 \% S R C, D=5 \%$ RRC, $E=10 \% R R C$

Performance of broiler chickens fed graded levels of rumen content based diets at the finisher phase

Table 4 shows the performance of broiler chickens fed on graded levels of rumen content based diets at finisher phase. The initial weight ranged from $668.75 \mathrm{~g}$ in birds on diet A to $611.67 \mathrm{~g}$ in chickens on diet $\mathrm{C}$. The means did not differ among the dietary treatments. Similarly, values of the final weight were not statistically different with the final weights varying from $2350.4 \mathrm{~g}$ in birds on diet B to $2257.8 \mathrm{~g}$ in chickens on $\operatorname{diet} \mathrm{A}$. The feed intake, daily weight gain and feed conversion rations were also not different statistically. The daily feed intakes were $151.59 \mathrm{~g}, 117.52 \mathrm{~g}, 137.59 \mathrm{~g}, 132.97 \mathrm{~g}$ and $135.45 \mathrm{~g}$ for diets A, B, C, D and E, respectively. While the highest daily weight gain value was obtained in birds on diet $\mathrm{B}$, the lowest value was obtained with diet $\mathrm{C}$. Furthermore, the feed conversion ratio obtained in birds on diet $\mathrm{C}$ with a value of 2.50 was found to be higher compared to 1.96 on $\operatorname{diet} \mathrm{B}$.

Table 4: Performance of broiler chickens fed graded levels of rumen content based diets at the finisher phase

\begin{tabular}{lccccccc}
\hline Parameter & A (0\%) & B (5\%) & C (10\%) & D (5\%) & E (10\%) & SEM & LS \\
\hline Initial weight & 688.75 & 666.67 & 611.46 & 639.58 & 661.54 & 36.56 & NS \\
Final weight & 2257.80 & 2350.40 & 2081.70 & 224.70 & 221.55 & 76.10 & NS \\
Daily feed intake & 151.59 & 117.52 & 137.59 & 132.97 & 135.69 & 13.50 & NS \\
Daily weight gain & 58.26 & 60.71 & 55.35 & 57.92 & 56.99 & 3.50 & NS \\
FCR & 2.47 & 1.96 & 2.50 & 2.45 & 2.15 & 0.23 & NS \\
Mortality & 6 & 9 & 4 & 8 & 5 & & \\
SEM= Standard Error of Mean; NS $=$ Not Significant, FCR $=$ Feed Conversion Ratio, & SRC = sun dried rumen \\
content; RRC $=$ roasted rumen content \\
$A=0 \% ; B=5 \%$ SRC, $C=10 \%$ SRC, $D=5 \%$ RRC, $E=10 \% R R C$
\end{tabular}

Overall performance of broiler chickens fed graded levels of rumen content based diets

The performance of broiler chickens fed graded levels of rumen content is presented in Table 5. All values were not significantly different between the dietary treatments. The final weight of the birds ranged from $1508.50 \mathrm{~g}$ on diet B to $1346.60 \mathrm{~g}$ for birds on diet C. The daily feed intakes were $100.00 \mathrm{~g}, 83.57 \mathrm{~g}, 93.56 \mathrm{~g}, 91.29 \mathrm{~g}$ and $92.55 \mathrm{~g}$ for diets $\mathrm{A}, \mathrm{B}, \mathrm{C}, \mathrm{D}$ and $\mathrm{E}$ respectively. The daily weight gain varied from $39.53 \mathrm{~g}$ in birds fed diet B to $36.34 \mathrm{~g}$ for birds on diet $C$. The highest feed conversion values were obtained in birds on $\operatorname{diet} C$ with a value of 2.69 and the lowest in $\operatorname{diet} B$ with a value of $2.33 \mathrm{~g}$. 
Umar, Daninna, Muazu, Kirfi, Abdullahi, Nuhu and Yakubu

Table 5: Overall performance of broiler chicken fed graded levels of rumen content based diets

\begin{tabular}{|c|c|c|c|c|c|c|c|}
\hline \multirow[b]{2}{*}{ Parameter } & \multirow[b]{2}{*}{$\mathrm{A}(0 \%)$} & \multicolumn{2}{|c|}{ SRC } & \multicolumn{2}{|c|}{ RRC } & \multirow[b]{2}{*}{ SEM } & \multirow[b]{2}{*}{ LS } \\
\hline & & B (5\%) & $\mathrm{C}(10 \%)$ & D (5\%) & E $(10 \%)$ & & \\
\hline Final weight & 1485.50 & 1508.50 & 1346.60 & 1443.00 & 1453.11 & 39.36 & NS \\
\hline Daily feed intake & 100.00 & 83.37 & 93.56 & 91.29 & 92.21 & 4.43 & NS \\
\hline Daily weight gain & 38.92 & 39.34 & 36.34 & 38.24 & 37.59 & 1.50 & NS \\
\hline FCR & 2.37 & 2.33 & 2.69 & 2.48 & 2.55 & 0.08 & * \\
\hline Mortality & 0 & 0 & 0 & 0 & 0 & 0 & \\
\hline
\end{tabular}

Based on the study findings, the data on the carcass weights of broilers at the end of the experiment (Table 6 below) revealed that there was no significant difference in the live weights of the broilers between the different treatments. However, birds fed with diet $\mathrm{E}$ had the least live weight (2100 g) whereas the highest value was recorded in birds fed with the control diet. A weight of $2350 \mathrm{~g}$ was obtained for both diets B and D. The plucked weights indicated that there was a significant difference $(\mathrm{p}<0.05)$ between the treatments. The weights of birds fed with diet $\mathrm{C}$ were similar to those of birds fed with diet $\mathrm{D}$. The highest plucked weights were recorded in birds fed with the control diet $(2220 \mathrm{~g})$ followed by birds fed with diet B (1999 g) while the least were observed in birds fed with diet E (1704 g). The carcass weights of the broilers revealed that there was no significant difference $(p>0.05)$ between all the treatments. Birds in the control diet with a $0 \%$ inclusion level of rumen content had the highest carcass weight $(1602 \mathrm{~g})$ while the least was recorded in $10 \% \mathrm{SRC}$ (diet C) with $1258 \mathrm{~g}$.

Table 6: Carcass, organs and gut weight expressed as percentage of live weight

\begin{tabular}{lllllll}
\hline Parameters & A & B & C & D & E & SEM \\
\hline Final live weight (g) & 2450.00 & 2350.00 & 2200.00 & 2350.00 & 2100.00 & $0.23^{\mathrm{NS}}$ \\
Pluck weight (g) & $2220.00^{\mathrm{c}}$ & $1999.00^{\mathrm{b}}$ & $1941.00^{\mathrm{ab}}$ & $1803.00^{\mathrm{ab}}$ & $1704.00^{\mathrm{a}}$ & $0.21^{*}$ \\
Carcass weight (g) & 1602.00 & 1424.00 & 1258.00 & 1277.00 & 1302.00 & $0.27^{\mathrm{NS}}$ \\
Dressing \% & 65.44 & 60.81 & 57.77 & 54.34 & 62.13 & $0.72^{\mathrm{NS}}$ \\
Liver weight (\%) & $2.54^{\mathrm{c}}$ & $1.57^{\mathrm{ab}}$ & $1.43^{\mathrm{a}}$ & $1.64^{\mathrm{a}}$ & $1.48^{\mathrm{ab}}$ & $0.00^{*}$ \\
Heart weight (\%) & $0.82^{\mathrm{b}}$ & $0.75^{\mathrm{b}}$ & $0.50^{\mathrm{a}}$ & $0.43^{\mathrm{a}}$ & $0.43^{\mathrm{a}}$ & $0.001^{*}$ \\
Spleen weight (\%) & $0.93^{\mathrm{c}}$ & $0.75^{\mathrm{b}}$ & $0.57^{\mathrm{ab}}$ & $0.58^{\mathrm{ab}}$ & $0.55^{\mathrm{a}}$ & $0.010^{*}$ \\
Gizzard weight (\%) & $4.10^{\mathrm{b}}$ & $4.22^{\mathrm{b}}$ & $3.86^{\mathrm{ab}}$ & $3.21^{\mathrm{a}}$ & $3.90^{\mathrm{ab}}$ & $0.093^{\mathrm{NS}}$ \\
Large intestine weight (\%) & $5.52^{\mathrm{b}}$ & $4.42^{\mathrm{a}}$ & $3.78^{\mathrm{a}}$ & $3.70^{\mathrm{a}}$ & $3.82^{\mathrm{a}}$ & $0.009^{*}$ \\
Small intestine weight (\%) & 1.47 & 1.49 & 1.34 & 1.28 & 1.33 & $0.793^{\mathrm{NS}}$ \\
Head and leg weight (\%) & 6.79 & 5.58 & 5.21 & 5.11 & 5.45 & $0.284^{\mathrm{NS}}$ \\
\hline
\end{tabular}

$\mathrm{a}, \mathrm{b}, \mathrm{c}=$ Means in the same row with different superscripts are significantly different $(p>0.05$;) NS $=$ Not

Significant, $S E M=$ Standard Error of Mean; SRC = Sundried Rumen Content RRC $=$ Roasted Rumen Content $A=0 \% ; B=5 \%$ SRC, $C=10 \%$ SRC, $D=5 \% R R C, E=10 \% R R C$

The organ weights, expressed as a percentage of live weights are shown in Table 6 above. There was a significant difference $(p<0.05)$ on values obtained for liver weights between the different treatments, with the highest percentage being recorded among birds fed the control diet while the least value was recorded in $\operatorname{diet} \mathrm{C}(1.43 \%)$ and then diet $\mathrm{E}$ with $1.48 \%$.
There were no significant differences $(p>0.05)$ in the heart weights between the treatments, with the highest percentage $(0.82 \%)$ value recorded in birds fed diets without the rumen content (control) whereas the least $(0.43 \%)$ was recorded at both diets of the RRC. On the other hand, the spleen weight values were significantly different $(p<0.05)$ between the treatments, with the 


\section{Performance and organ characteristics of broiler chickens fed varying levels of rumen content}

control diet having the highest spleen weight $(0.93 \%)$ followed by the $5 \%$ SRC (diet B) with $0.74 \%$. The least value $(0.55 \%)$ of spleen weight was obtained with diet $\mathrm{E}$. The gizzard weights in relation to live weights indicated a non-significant difference between the treatments $(\mathrm{p}>0.05)$. Birds fed with 5\% sun dried rumen content (diet B) had the highest value of $4.3 \%$ of gizzard weight followed by the control group while the least among the values obtained was observed in birds fed 5\% RRC (3.210\%). The $10 \%$ SRC and 10\% RRC (C and $\mathrm{E}$ ) diets recorded values of $3.86 \%$ and $3.90 \%$ respectively. The results also indicated that there were significant differences $(p<0.05)$ in the large intestine weights recorded. Birds with $5.52 \%$ on the control treatment had the highest value while birds fed with 5\% RRC had the least percentage large intestine weights of $3.70 \%$. The small intestine weights had no significant differences between the treatments and the weights ranged from $1.49 \%$ to $1.28 \%$ of live weight, where the highest value was recorded for birds fed with the 5\% SRC diet. Furthermore, birds fed with $10 \%$ SRC had the least percentage of the head and leg weights (5.21\%) whereas the highest percentage of head and leg weights were recorded for birds fed with the control diet $(6.790 \%)$. There were no significant differences $(p>0.05)$ in the percentage weights of legs and heads of the broilers on different treatments.

\section{Discussion}

The daily feed intake was not significantly different between all the dietary treatments in the starter (49.42-50.74 g) and finisher (117.52-151.59 g) phases. This result was in conformity with the findings of Adeniji and Jimoh (2007), who fed different inclusion levels of rumen content to pullet chicks and obtained similar values of feed intake. The daily weight gains observed at the starter (49.42-50.74 g) and finisher
(117.52-151.59 g) phases were not affected by the dietary levels of inclusion of rumen content. A similar trend was also found at the overall weight gain (36.34-39.53 g). In contrast to these findings, Yakubu et al. (2007) reported that, broiler chickens fed urea treated rumen content at $12 \%$ showed a significantly higher carcass yield and liver weight. This difference could be due to the urea treatment done to the rumen content. The feed conversion ratio at the starter (2.26-2.87) and finisher (1.96-2.5) phases were statistically similar among the dietary treatments. However, there was a significant difference among the treatments at the overall feed conversion ratio. The values obtained for the final live weight indicated that there was no significant difference $(p>0.05)$ in the final live weight of broiler chickens fed the differently processed rumen content. The findings agreed with the earlier work of Gwayo et al. (2006) who reported no significant difference in the final live weight of broilers fed different inclusion levels of goat rumen digesta. Also, the finding was in line with $\mathrm{t}$ Elfaki et al. (2015) that there is no significant difference on the live weight of broilers fed with dietary processed dried rumen content. The findings indicate that the significant difference $(\mathrm{p}<0.05)$ among the treatments on the percentage plucked weight did not agree with the observation made by Gwayo et al. (2006), who observed no significant difference between the control group and the treatment groups fed rumen digesta as a replacement for wheat offal as a dietary fibre source at both starter and finisher phases. The experiment carried out on the carcass weights had no significant $(p>0.05)$ effect on the percentage live weights of broilers fed with sun dried and roasted rumen content. This agreed with the earlier work of Elfaki et al. (2015) that there was no observable difference in the carcass weights of broilers fed dietary treated rumen content. Table 6 
shows the organ weights of broilers at the end of the research. The gizzard weight was not different between all means and ranged from $(4.22$ to $3.21 \%)$. On the other hand, Gwayo et al. (2006) reported differences in weights of gizzard and the heart while all other organs were not significantly different. This may likely be due to differences in the processing method and the source of biodigesta between the two studies. However, the results agreed with the findings made by Elfaki et al. (2015) that there was no significance difference in the weights of spleens between the treatment groups. The result on the weights of the small intestines indicated no significant difference $(p>0.05)$ between the treatment means and thus agreed with observations made by Elfaki et al. (2015).

\section{Conclusion and recommendation}

The results of the study indicated that dried rumen content can be incorporated in broiler diets at $10 \%$ replacement level of wheat offal without adverse effects on carcass yield. Therefore, using rumen biodigesta in poultry diet could reduce the cost of feeding and subsequently prevent environmental pollution which the biodigesta may have caused. Furthermore, up to $10 \%$ of dried rumen content can be used as a cheap source of energy and protein for poultry, though, its inclusion must be done with caution, as studies have not yet determined the microbial impact it might have. As such, the need for more researches cannot be over emphasised.

\section{References}

Atteh, J. O. 2003. Romancing the chicken 68th Inaugural lecture, University of Ilorin, Nigeria. Published by Unilorin Press.

Adeniji, A. A. and Jimoh, A. 2007. Effects of replacing maize with enzymesupplemented bovine rumen content in the diets of pullet chicks.
International Journal of Poultry Science, 6: 814-817.

Aremu, A., Adamu, I. Z., Shiwoya, I. I. and Ayamwale, B. A. 2010. Cost benefit ratio of varying levels of energy and protein diets under single versus double phase feeding. Infrastructuring animal agricultural in a challenged economy. Proceedings of Nigerian society for animal production. March 14th 17th, 2010. Edited by O. J. Babayemi., O. A. Abu University of Ibadan. Nigeria. 88-291.

Biobaku, W. O., Aina, A. B. J. and Shoge, A. O. 1999. The use of Activated Sewage Sludge in Broiler Diets. Nigerian Journal of Animal Production, 26: 84.

Bauchi State Agricultural Development Programme 1993. Development Statistics. BSADP, Bauchi, Nigeria.

Dairo, F. A. S., Aina, O. O. and Asafa, A. R. 2005. Performance evaluation of growing rabbits fed varying levels of rumen content and blood-rumen content mixture. Nigerian Journal of Animal Production, 32 (1): 67-72.

Elfaki, M. O. A., Abdelatti, K. A. and Malik, H. E. 2015. Effect of Dietary Dried Rumen Content on Broiler Performance, Plasma Constituents and Carcass Characteristics. Global Journal of Animal Scientific Research.3(1): 264-270.

Emmanuel, B., 1978. Effects of Rumen Contents or Fraction thereof on Performance of Broilers. British Poultry Science, 19: 13-16.

Esonu, B. O., Ogbonna, U. D., Anyanwu, G. A., Emenalom, O. O., Uchegbu, M. C., Etuk, E. B. and Udedibie, A. B. 2006. Evaluation of performance, organ characteristics and economic analysis of broiler finisher fed dried rumen digesta. International Journal of Poultry Science, 5: 1116- 
1118.

Gwayo, G. J., Adebola, I. A., Egbo, M. L. and Doma, U. D. 2006. The Effects of Varying Levels of Dietary Goat Rumen Content on the Performance of Broiler Chicken, Proceedings of 11th Annual Conference of Animal Science Association of Nigeria (ASAN) 2006, Sept. 18th-21st, I. A. R. and T Ibadan, Nigeria. Pp. 104107, 2006.

Makinde, A. O., Sonaiya, B. and Adeyeye, S. 2008. Conversion of Abattoir Wastes into Livestock Feed: Chemical Composition of Sun-Dried Rumen Content Blood Meal and its Effect on Performance of Broiler Chickens. A paper presented at the Conference on International Research on Food Security, Natural Resource Management and Rural Development. University of Hohenheim, October 7-9, Tropentag, 2008.

McDonald, P., Edward, R. A. and Greenhalgh, J. F. D. 1990. Voluntary food intake. In: Animal Nutrition 4th edition. Pp375-397. Longman Sci. Tech. UK.
Mendel, F. 2013. Rice Brans, Rice Bran Oils, and Rice Hulls: Composition, Food and Industrial Uses, and Bioactivities in Humans, Animals, and Cells. Journal of Agricultural and Food Chemistry, 61 (45): 10626 $-10641$.

Odunsi, A. A., Akingbade, A. A. and Farinu, G. O. 2004. Effect of bovine blood-rumen digesta mixture on growth performance, nutrient retention and carcass characteristics of broiler chickens. Journal of Animal and Veterinary Advances, 3 (10): 663-667.

Yakubu, B., Adegbola, T. A., Bogoro, S., Yusuf, H. B. 2007. Effect of urea treated and untreated rice offal on the performance of broilers: growth performance and economy of production. Journal of Sustainable Development of Agriculture \& Environment, 3:7-13.

Received: $10^{\text {th }}$ October, 2019 Accepted: $13^{\text {th }}$ January, 2020 